\title{
TOXOPLASMOSE EM ANIMAIS SILVESTRES E DOMÉSTICOS DA REGIĀO DE BOTUCATU, ESTADO DE SÃO PAULO, BRASIL
}

Ednir Salata (1), Elizaide L. A. YOShIda (1), Elói A. PEREira (2) e Fernando M. A. CoRREA (3)

\section{R E S U IM O}

Os Autores analisaram soros de 47 Cannis familiaris, de 9 Felis cattus, de 64 Didelphis marsupialis aurita, de 9 Dasypus novemcinctus, de 4 Cabassous tatouay e de 29 Rattus rattus, através da reação de imunofluorescência indireta, para pesquisar a presença de anticorpos anti Toxoplasma gondii. Estes foram encontrados apenas em C. familiaris $(63,8 \%)$ e em D. m. aurita $(4,7 \%)$. Frente aos resultados obtidos, os Autores sugerem que novas pesquisas nesta área sejam realizadas, para que se conheça melhor a importância epidemiológica de várias espécies animais na disseminação da toxoplasmose.

\section{INTRODU GAO}

Mesmo após a descoberta do oocisto de To. xoplasma gondii, pouco se conhece sobre os aspectos relacionados à epidemiologia da toxoplasrnose. Sabe-se que, de modo geral, são os felídeos os hospedeiros definitivos ${ }^{7}$ do Toxoplasma gondii e que várias espécies de animais atuam como hospedeiros intermediários facultativos $3,5,6,8,11,12$. Estes desempenham papel de grande importância na transmissão da toxoplasmose, na medida em que sua carne é ingerida pelo homem ou por outros animais. Pois, mesmo em comunidades onde felídeos só vivem de modo selvático, a frequiência de reações sorológicas positivas em seres humanos. para essa parasitose, é elevada.

\section{MATERIAL E IMETODOS}

\section{Procedência e captura dos animais}

Os cães e gatos, sem raças definidas, foram apreendidos nas ruas de Botucatu. Esta cidade situa-se na serra de Botucatu, numa altitude variável entre 777 e 885 metros, a $22^{\circ} 52^{\prime} 20^{\prime \prime}$ de latitude sul e $48^{\circ} 26^{\prime} 30^{\prime \prime}$ de latitude W., com temperatura média anual entre $17^{\circ}$ e $22^{\circ} \mathrm{C}$.
Os tatús, gambás e ratos, foram capturados com armadilhas de gaiola, que permitem a captura de animais vivos ${ }^{16}$, no Bairro São João, Município de Conchas. O Bairro localiza-se ao lado do $\mathrm{Km} 205$ da rodovia Marechal Rondon, apresenta altitude de $470 \mathrm{~m}$, temperatura média anual entre $19^{\circ}$ e $21^{\circ} \mathrm{C}$ e a queda pluviométrica média foi de $1090,6 \mathrm{~mm}$ na época de captura dos animais.

\section{Amostras de soros}

Utilizamos soros de 47 Cannis familiaris (cão doméstico), de 9 Felis cattus (gato doméstico), de 56 Didelphis marsupialis aurita (gambá), de 9 Dasypus novemcinctus (tatú) e de 4 Cabassous tatouay (tatú). Utilizamos ainda sangue, colhido em papel de filtro, de 8 Didelphis marsupialis aurita e de 29 Rattus rattus, seguindo técnica descrita por SOUZA \& CAMARGO 15. Após eluição este material nos forneceu eluato na diluição inicial de 1/20. Os soros foram usados a partir da diluição inicial de $1 / 8$.

Tanto as amostras de soro, como as de sangue colhido em papel de filtro, foram coletadas imediatamente após a captura dos ani-

(1) Professor Assistente do Departamento de Parasitologia do IBBMA - UNESP - BOTUCATU

(2) Preparador Técnico

(3) Professor Titular do Departamento de Parasitologia do IBBMA - UNESP - BOTUCATU 
SALATA, E; YOSHIDA, E. L. A.; PEREIRA, E. A. \& CORREA, F. M: A. - Toxoplasmose em animais silvestres e domésticos da região de Eotucatu, Estado de São Paulo, Brasil. Rev. Inst. Med. trop. São Paulo. 27:20-22, 1985.

mais, o que eliminou a possibilidade de infecção em cativeiro.

\section{Conjugados fluorescentes}

Conjugados antiglobulinas, específicos para as diferentes espécies de animais, foram preparados por imunização de coelhos com globulinas obtidas por precipitação com solução saturada de sulfato de amônio, como preconizado por MELLORS 10. De soros antiglobulínicos com titulos de $1 / 16$ ou superiores, revelados através da imunodifusão radial dupla, obtivemos a fração globulínica à qual conjugamos o isotiocianato de fluoresceína, pela técnica de diálise, para obtenção de conjugados fluorescentes, como preconizado por CAMARGO ${ }^{2}$.

\section{Antígeno}

A cepa de Toxoplasma gondii utilizada, segundo os Autores nos foi fornecida gentilmente pela Dra. Lígia Jamra, do Instituto de Medicina Tropical de São Paulo (cepa N), isolada de um coelho por NóBREGA, em 1972, e vem sendo mantida, por passagens semanais, em camundongos albinos.

Utilizamos como antígeno, as formas trofozoíticas obtidas de exsudato peritoneal de camundongos previamente inoculados. Tais formas foram tratadas de acordo com as recomenciações de CAMARGO ${ }^{2}$.

\section{Reação de imunofluorescência}

Utilizamos a técnica de imunofluorescência indireta (RIFI), segundo CAMARGO ${ }^{2}$.

\section{RESULTADOS}

Dos 162 animais examinados, apenas 30 pertencentes a uma espécie de hábitos domiciliares e 3 de hábitos peridomiciliares ou selváticos apresentaram soros positivos à RIFI, ainda que não superiores a $1 / 16$, como mostrado na Tabela I.

\section{DISGUSSÃO}

Nossos resultados, ao contrário do que já foi observado no nosso meio 6,12 , revelaram ausência de reaçóes positivas, a partir de $1 / 8$, em felídeos.
T A B E L A I

Número e porcentagem de diferentes espécies animais com RIFI positiva ao antígeno de Toxoplasma gonłlii

\begin{tabular}{|c|c|c|c|}
\hline Espécies & $\begin{array}{l}\text { RIFI } \\
\text { Número }\end{array}$ & $\begin{array}{l}1 / 8 \\
\text { Porcentagem }\end{array}$ & Totais \\
\hline C. familiaris & 30 & 63,8 & 47 \\
\hline F. cattus & 00 & 00,0 & 09 \\
\hline D.m. aurita & 03 & 04,7 & 64 \\
\hline D. novemcinctus & 00 & 00,0 & 09 \\
\hline C. tatouay & 00 & 00,0 & 04 \\
\hline R. rattus & 00 & 00,0 & 29 \\
\hline Totais & 33 & 20,1 & 162 \\
\hline
\end{tabular}

No que se refere à espécie canina o porcentual de positividade, em soros diluidos a $1 / 8$, foi relativamente alto $(63,81 \%)$, o que está de acordo com os dados citados na literatura 3,6,13. Tal fato se reveste de importância epidemiológica, visto que cães geralmente vivem associa. dos ao homem.

Trabalhando com animais silvestres e domésticos em São Paulo, SOGORB \& col. 12,14, encontraram $100 \%$ de Didelphis azarae e $66,6 \%$ de Dasypus novemcinctus positivos à reação de Sabin \& Feldman, o que é significantemente diferente de nossos resultados, que revelaram entre os animais com hábitos selváticos um porcentual de positividade, à RIFI, relativamente baixo, como se pode verificar na Tabela I.

Por outro lado, apesar da especificidade da reação de imunofluorescência indireta para diagnóstico da toxoplasmose ter sido sugerida por DOBY \& BEAUCOURNU ${ }^{4}$ e MARKUS ${ }^{9}$ convém salientar que mesmo uma reação negativa pode não excluir o parasitismo pelo Toxoplasma gondii.

Tais fatos sugerem a necessidade de se continuar a pesquisar a infecção em a natureza, de diferentes espécies animais de diversas regiōes, para que possamos conhecer melhor os aspectos relacionados à disseminação da toxoplasmose e à contribuição particular de cada espécie animal.

\section{SUMMARY}

Toxoplasmosis in wild and domestic animals from the Botucatu area (São Paulo, Brazil)

Sera from 47 Cannis familiaris, 9 Felis cattus, 64 Didelphis marsupialis, 9 Dasypus novemcinctus, 4 Cabassous tatouay and 29 Rattus rat- 
SALATA, E.; YOSHIDA, E. L. A.; PEREIRA, E. A. \& CORREA, F. M. A. - Toxoplasmose em animais silvestres e do-

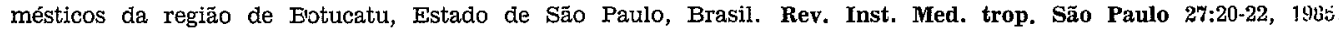

tus were examined for anti-Toxoplasma gondii antibodies by the indirect immunofluorescence reaction. Only two species were positives: C. familiaris $(63.8 \%)$ and D.m. aurita $(4.7 \%)$. For a better knowledge of the importance of the various animals species in toxoplasmosis dissemination the Authors suggest further researchs on this subject.

\section{REFERENCIAS BIBLIOGRAFICAS}

1. AWAD, F. I. \& LAINSON, R. - A note on the serology of sarcosporidiosis and Toxoplasmosis. J. Clin. Path. 7: 152-156, 1954.

2. CAMARGO, M. E. - Introdução às técnicas de imunofluorescência. São Paulo, Instituto de Medicina Tropical de São Paulo, 1971. (mimeogr.).

3. COUTINHO, S. G.; ANDRADE, C. M.; LOPES, A. C.; CHIARINI, C. \& FERREIRA, L. F. - Observaçōes sobre a presença de anticorpos para Toxoplasma gondji em cães de área suburbana do Rio de Janeiro. Rev. Soc. Bras. Med. trop. 2: 285-295, 1968.

4. DOBY, J. M. \& BEAUCOURNU, J. C. - Absence de réactions croisées en immunofluorescence indirecte ertre sérum de porteurs de Isospora hominis et antigènes Toxoplasma. Bull. Soc. Path. Exot. 65: 404-409, 1972.

5. EYLES, D. E.; GIBSON, C. L.; COLEMAN, N.; SMITH, C. S.; JUMPER, J. R. \& JONES, F. E. - The prevalence of toxoplasmosis in wild and domesticated animals of the Memphis Region. Amer. J. trop. Med. 8: $505-510,1959$

6. FERNANDES, W. J. \& BARBOSA, W. - Toxoplasmose. Notas sobre sua ocorrência em animais domésticos em Goiânia (1970). Rev. Pat. trop. 1: 259-235, 1972 .
7. FRENKEL, J. K.; DUBEY, J. P. \& MILLER, N, L. - Toxoplasma gondii in cats: fecal stages identified as coccidian oocyst. Science 16\%: 893-896, 1970.

8. HOARE, C. A. - Toxoplasmosis in animals. Vet. Rev. Annot. 2: 25-34, 1956.

9. MARKUS, M. B. - Serology of Toxoplasmosis, Isosporosis and Sarcosporidiosis. New Engl. J. Med. 289: $980-981,1973$.

10. MELLORS, R. C. - Analytical Cytology. 2. Ed. New York, McGraw Hill, 1959. In Oliveira Lima, A. \& Dias da Silva, W. - Imunologia, Imunopatologia e Alergia. 1. ${ }^{\circ}$ Ed. Rio de Janeiro, Guanabara Koogan S.A.

11. MILLER, L. T. \& FELDMAN, H. A. - Incidence of antibodies for Toxoplasma among various animals species. J. Infect. Dis. 92: 118-120, 1953.

12. SOGORB, S. F.; JAMRA, L. F.; GUIMARĀFS, E. C. \& DEANE, M. P. - Toxoplasmose expontânea em animais domésticos e silvestres em São Paulo. Rev. Inst. Med. trop. São Paulo 14: 314-320. 1972.

13. SOGORB, S. F.; JAMRA, L. F. \& GUIMARÃES, E. C. - Toxoplasmose em cães de São Paulo. Rev. Inst. Med. trop. São Paulo 18: 36-41, 1976.

14. SOGORB, S. F.; JAMRA, L. F. \& GUIMARAES, E. C. - Toxoplasmose em animais de São Paulo, Brasil. Rev. Inst. Med. trop. São Paulo 19: 191-194, 1977.

15. SOUZA, S. L. \& CAMARGO, M. E. - The use of filter paper blood smears in a practical fluorescent test for American trypanosomiasis serodiagnosis. Rev. Inst. Med. trop. São Paulo 8: 255-258, 1966.

1î. VANZOLINI, P. E. \& PAPAVERO, N. - Manual de coleta e preparação de animais terrestres e de água doce. Publicação do Departamento de Zoologia, Se. cretaria da Agricultura do Estado đe São Paulo, 1967.

Recebido para publicação em 13/1/1984 